nomenon but at least in Nottingham it seems to encompass heart attacks in the lay mind. Our study suggests that there is no point in sending a coronary ambulance in response to an emergency call for a patient with anything other than a collapse, and if the telephone operator can elicit a history with an absence of chest pain it looks as if it will be unprofitable to despatch the special vehicle.

Initial experience suggests that our method of identifying patients with heart attacks from emergency calls made by members of the public is working reasonably well. As it is virtually only such calls that involve patients with symptoms for a very short period we believe it is particularly important to use our special vehicle in this way.

Possibly a call-selection system might be further refined if the general public were educated about the symptoms of heart attacks and the need for urgent treatment, but any educational programme would probably increase the number of calls (both genuine and false) for the ambulance and the service might well become swamped. We do not believe that the value of a coronary ambulance service is yet sufficiently well established to justify a programme of mass education.

We thank the personnel of the Nottingham city ambulance service for their help, Dr. W. H. Parry (at the time of this study Medical Officer of Health, Nottingham), Mr. P. Weston (consultant in charge of the accident and emergency department at Nottingham General Hospital), and the physicians of the Nottingham General Hospital.

Requests for reprints should be addressed to Dr. J. R. Hampton, Department of Medicine, Nottingham General Hospital, Nottingham NG1 6HA.

\section{References}

1 Adgey, A. A. J., et al. (1971), Lancet, 2, 7723.

Dewar, H. A., McCullom, J. P. K., and Floyd, M., British Medical Fournal, $1969,4,226$.

3 Gearty, G. F., et al., British Medical fournal, 1971, 3, 33.

4 Sandler, G., and Pistevos, A., British Heart fournal, 1972, 34, 1283.

5 White, N. M., et al., British Medical fournal, 1973, 3, 618 .

\title{
Effects of Ambulance Transport in Critically Ill Patients
}

\author{
G. WADDELL, P. D. R. SCOTT, N. W. LEES, I. MCA. LEDINGHAM
}

British Medical fournal, 1975, 1, 386-389

\section{Summary}

Two groups of critically ill patients were transferred by ambulance from other hospitals to a central intensive therapy unit. The effect of transport was reviewed retrospectively in 46 patients and prospectively in 20 patients. Of the 46 patients reviewed retrospectively six became hypotensive, six became hypertensive, and seven developed delayed hypotension. One patient developed fits and six out of 13 patients had a rise in arterial $\mathrm{PCO}_{2}$ of $1.6-4 \cdot 1 \mathrm{kPa}(12-31 \mathrm{~mm} \mathrm{Hg})$.

Of the 20 patients reviewed prospectively, one patient became hypertensive due to overtransfusion, one had a fit, but none became hypotensive. Three out of four cases of delayed hypotension were related to starting intermittent positive pressure ventilation. Arterial $\mathrm{PCO}_{2}$ fell in one patient and arterial $\mathrm{PCO}_{2}$ rose in two, each change being related to changed oxygen therapy or narcotics. There were no changes in other cardiovascular or respiratory indices, body temperature, or urine production.

Earlier transfer, resuscitation before transfer, continuing medical care during the journey, and hence a slower smoother journey seemed to be important factors in the management of these patients. Our findings may have important implications in the future regional organization of the care of critically ill patients.

\section{Introduction}

With categorization of hospitals and increasing specialization

University Department of Surgery, Western Infirmary, Glasgow G11 6NT

G. WADDELL, M.B., F.R.C.s., Senior Orthopaedic Registrar

P. D. R. SCOTT, M.B., F.R.C.S., Orthopaedic Registrar

N. W. LEES, M.B., F.F.A. R.C.S., Senior Anaesthetic Registrar

I. McA. LEDINGHAM, M.B., CH.B., Senior Lecturer and Consultant Clinical Physiologist transfer of critically ill patients between hospitals is likely to become more frequent. Thus detailed knowledge of the effects of transport is essential.

Most previous studies have dealt with primary evacuation of patients in an unstable condition from roadside or home. ${ }^{1-3}$ Isolated instances of collapse seem to have been related to sudden jolting of the ambulance, ${ }^{245}$ but the lack of any pretransfer baseline data makes conclusions difficult. Secondary evacuation between hospitals of selected groups of ill patients is reported in several French studies. ${ }^{5-10}$ Serious collapse, arrhythmias, cardiac arrest, acute respiratory insufficiency, or fits occurred in $5 \%$ of such patients, and $15-30 \%$ developed mild hypotension. These reports, however, were generally retrospective clinical studies and gave few objective data.

\section{Retrospective Review}

In six years 67 patients were transferred by ambulance from other hospitals to the intensive therapy unit of the Western Infirmary, Glasgow. Adequate records were available on 46.

The primary clinical conditions for which transfer was deemed necessary are indicated in table $I$. Though there were no statistically significant changes in mean heart rate or systolic blood pressure as a result of the journey considerable variation in haemodynamic response occurred from patient to patient. Twenty-seven patients had no change in heart rate or systolic blood pressure. In six patients a raised systolic blood pressure of $30-50 \mathrm{~mm} \mathrm{Hg}$ occurred which settled spontaneously in two to four hours (fig. 1). In six patients a fall in blood pressure of more than $40 \mathrm{~mm} \mathrm{Hg}$ occurred. Since urgent treatment was required to correct this hypotension spontaneous recovery could not be assessed (fig. 2). A delayed fall in systolic blood pressure of $20-30 \mathrm{~mm} \mathrm{Hg}$ occurred one to one and a half hours after transfer in seven patients (fig. 3), possibly related to a change in treatment after arrival at the intensive therapy unit. One previously stable patient developed fits and tachycardia 14 minutes after the journey. The distribution of these patterns of response within the series is shown in table I. Septic shock seemed particularly likely to be associated with either hypertension or hypotension, and patients with chest injuries seemed more likely to develop hypertension. 
TABLE I-Primary Condition and Cardiovascular Response to Ambulance fourney in Two Study Groups. Results are Numbers of Patients

\begin{tabular}{|c|c|c|c|c|c|c|c|c|}
\hline \multirow[b]{2}{*}{$\begin{array}{c}\text { Primary } \\
\text { Condition }\end{array}$} & \multicolumn{4}{|c|}{ Retrospective Study $(n=46)$} & \multicolumn{4}{|c|}{ Flying-squad Study $(n=20)$} \\
\hline & $\begin{array}{c}\text { No } \\
\text { Change }\end{array}$ & Hypertension & Hypotension & $\begin{array}{c}\text { Delayed } \\
\text { Hypotension }\end{array}$ & $\begin{array}{c}\text { No } \\
\text { Change }\end{array}$ & Hypertension & Hypotension & $\begin{array}{c}\text { Delayed } \\
\text { Hypotension }\end{array}$ \\
\hline $\begin{array}{l}\text { Cardiac Shock } \\
\text { Haemorrhagic }\end{array}$ & 4 & 0 & 0 & 1 & 1 & 0 & 0 & 0 \\
\hline $\begin{array}{l}\text { Shoock } \\
\text { Septic Shock } \\
\text { Respiratory }\end{array}$ & $\begin{array}{l}2 \\
3\end{array}$ & $\begin{array}{l}0 \\
2\end{array}$ & $\begin{array}{l}1 \\
3\end{array}$ & $\begin{array}{l}1 \\
0\end{array}$ & $\begin{array}{l}3 \\
5\end{array}$ & $\begin{array}{l}0 \\
1\end{array}$ & $\begin{array}{l}0 \\
0\end{array}$ & $\begin{array}{l}0 \\
1\end{array}$ \\
\hline $\begin{array}{l}\text { failure } \\
\text { Chest injury }\end{array}$ & $\begin{array}{l}7 \\
5\end{array}$ & $\begin{array}{l}0 \\
4\end{array}$ & $\begin{array}{l}2 \\
0\end{array}$ & $\begin{array}{l}1 \\
1\end{array}$ & $\begin{array}{l}4 \\
0\end{array}$ & $\begin{array}{l}0 \\
0\end{array}$ & $\begin{array}{l}0 \\
0\end{array}$ & $\begin{array}{l}2 \\
0\end{array}$ \\
\hline Coma & 5 & 0 & 0 & 2 & 1 & 0 & 0 & 1 \\
\hline Renal failure & 1 & 0 & 0 & 1 & 1 & 0 & 0 & 0 \\
\hline Total & 27 & 6 & 6 & 7 & 15 & 1 & 0 & 4 \\
\hline
\end{tabular}

In the 13 patients for whom complete data were available there were no statistically significant changes in mean respiratory rate or arterial blood gases (table II), but six of the patients had a rise in arterial $\mathrm{PCO}_{2}$ of $1 \cdot 6-4 \cdot 1 \mathrm{kPa}(12-31 \mathrm{~mm} \mathrm{Hg})$. In 28 patients with temperature readings mean oral temperature before transfer was $36.5^{\circ} \mathrm{C}$ and mean rectal temperaure after transfer was $36 \cdot 8^{\circ} \mathrm{C}$. Patients whose temperature was $36 \cdot 1^{\circ} \mathrm{C}$ or less had a higher incidence of immediate cardiovascular

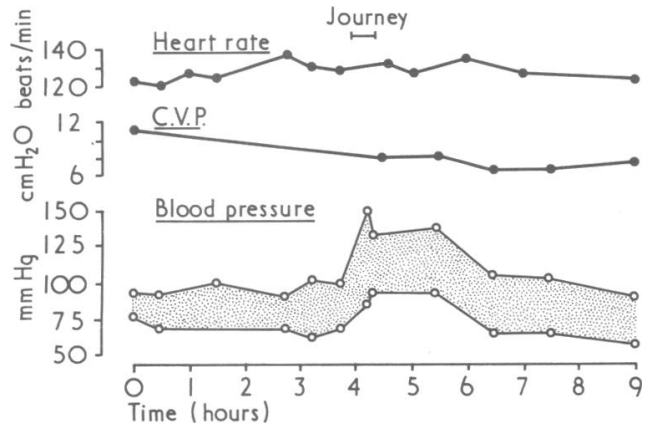

FIG. 1-Retrospective study. One patient's hypertensive response to ambulance journey.

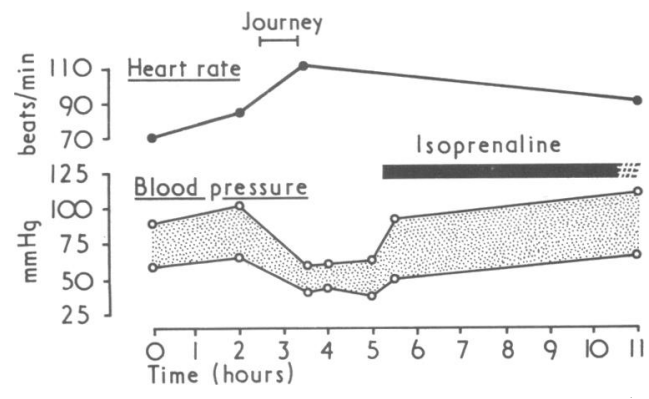

FIG. 2-Retrospective study. One patient's hypotensive response to ambulance journey.

response to the journey, but this was not statistically significant. No other pretransfer index was of any prognostic value.

No deaths occurred within 20 hours of the journey. The final mortality of transferred patients was comparable to that of similar patients treated in the unit who had initially been admitted to the Western Infirmary. The mortality in patients who developed hypertension $(67 \%)$ or hypotension $(50 \%)$ was significantly higher $(P<0.05)$ than in patients with no change $(31 \%)$ or delayed hypotension $(29 \%)$. This may simply mean that more severely ill patients are more likely to show an immediate cardiovascular response to the journey.

\section{Prospective Study}

The intensive therapy unit "flying squad" consisted of one or two

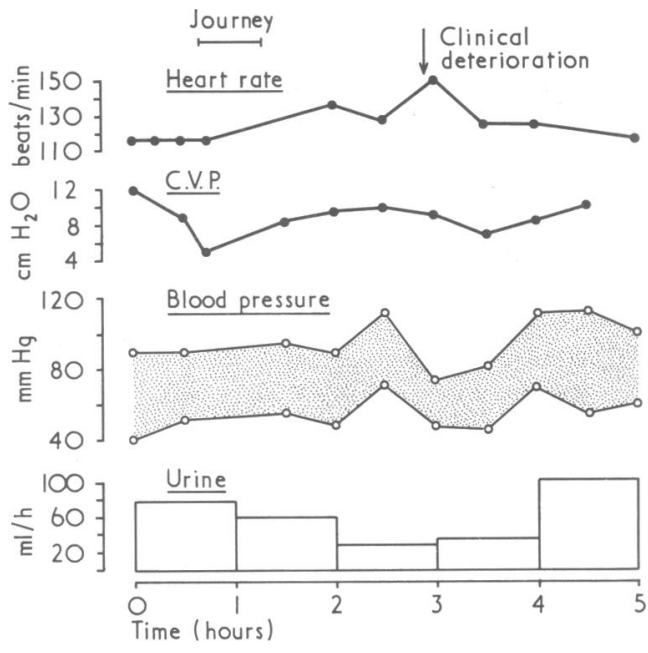

FIG. 3-Retrospective study. One patient's delayed hypotensive response to ambulance journey.

members of a previously described "shock team."11 When the intensive therapy unit received a request for a transfer the flying squad travelled to the referring hospital, set up monitoring equipment, and began treatment. They accompanied the patient in an ambulance of standard design and continued treatment on arrival at the unit.

Readings of heart rate, blood pressure, central venous pressure (C.V.P.), toe temperature, and respiratory rate were made every quarter of an hour for one hour before the journey, in the ambulance at the start and finish of the journey, and for two hours thereafter. Heart rate was measured by palpation of the pulse or counting from the E.E.G. Blood pressure was measured by arm cuff, mercury manometer, and auscultation. C.V.P. was measured by a saline manometer connected to a central venous catheter whose position was confirmed by chest $x$-ray examination. The zero reference was the mid-axillary line in the fifth interspace. Toe temperature was measured by a Grant thermometer with a small thermistor taped to the big toe (accuracy $\pm 0.3^{\circ} \mathrm{C}$ ). Respiratory rate was counted.

Rectal temperature was recorded on the Grant thermometer using a rectal thermistor taped in position (accuracy $\pm 0.3^{\circ} \mathrm{C}$ ). Readings were made one hour before, immediately before, immediately after, and one and two hours after the journey. A 20-second, lead-II E.C.G. was recorded at the same intervals on a portable batteryoperated recorder (Transite II). The bladder was catheterized and emptied and urine production measured over the hour before transfer, the period of the journey, and two hours afterwards. Fluid transfused was recorded over the same periods.

A 2-ml heparinized sample of arterial blood was taken by radial stab immediately before the journey. The syringe was sealed with a plastic cup and stored in a vacuum flask containing ice and water. A second sample was taken immediately after the journey. Blood gases on the two samples were measured using standard apparatus (Radiometer system). Preliminary experiments showed that storage in this manner for up to two hours did not introduce clinically significant errors in $\mathrm{pH}, \mathrm{PCO}_{2}$, or $\mathrm{Po}_{2}$.

Two groups of patients were studied prospectively-21 critically ill patients transferred from other hospitals to the intensive therapy unit of the Western Infirmary, Glasgow, and 20 convalescent surgical patients. 
In the first group one patient was considered unsuitable for transfer-after ventricular fibrillation during tonsillectomy. She was unresponsive to pain, had fixed dilated pupils, no spontaneous respiration, a systolic blood pressure of $40-50 \mathrm{~mm} \mathrm{Hg}$, a bizarre E.C.G., and a rectal temperature of $35^{\circ} \mathrm{C}$. She died within 30 minutes of this decision. The clinical conditions in the 20 patients who were transferred were comparable to those of patients in the retrospective study excep that there were no chest injuries. Fifteen patients were transported two miles and five from four and a half to 13 miles. The average ambulance ride was 12 minutes and the total time from bed to bed 33 minutes.

The 20 convalescent surgical patients were studied over the same two-mile distance as that covered by the 15 patients of the first group. Similar but non-invasive measurements were made of heart rate, blood pressure, E.C.G., respiratory rate, and rectal and toe temperatures.

TABLE II-Mean Respiratory Rate and Arterial Blood Gases Before and After Transfer in Two Study Groups

\begin{tabular}{|c|c|c|c|c|}
\hline & \multicolumn{2}{|c|}{ Retrospective Study $(n=13)$} & \multirow{2}{*}{$\begin{array}{c}\text { Flying-squad } \\
\text { Before } \\
\text { Transfer }\end{array}$} & \multirow{2}{*}{ 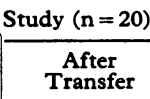 } \\
\hline & $\begin{array}{c}\text { Before } \\
\text { Transfer }\end{array}$ & $\begin{array}{c}\text { After } \\
\text { Transfer }\end{array}$ & & \\
\hline $\begin{array}{l}\text { Respiratory } \\
\text { rate/min } \\
\text { pH } \\
\mathrm{PCO}_{3}(\mathrm{kPa}) \\
\mathrm{PO}_{2}(\mathrm{kPa}) \\
\mathrm{Base}^{2} \text { excess } \\
(\mathrm{mmol} / \mathrm{l})\end{array}$ & $\begin{array}{l}33 \\
7 \cdot 35 \\
6 \cdot 1 \\
8 \cdot 0 \\
-2\end{array}$ & $\begin{array}{l}30 \\
7 \cdot 35 \\
6 \cdot 9 \\
8 \cdot 7 \\
0\end{array}$ & $\begin{array}{l}26 \\
7 \cdot 35 \\
5 \cdot 5 \\
13 \cdot 6 \\
-2\end{array}$ & $\begin{array}{c}28 \\
7 \cdot 39 \\
5.5 \\
12 \cdot 9 \\
-1\end{array}$ \\
\hline
\end{tabular}

Conversion: SI to traditional Units

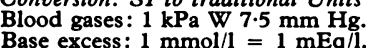

\section{Results}

The 20 convalescent surgical patients did not show clinically significant changes in any variable, either individually or mean.

There was no change in the mean cardiovascular values of the 20 critically ill patients transferred (fig. 4). Unlike the patients in the retrospective survey, variations in haemodynamic response from patient to patient in the prospective study were minimal. In no patient did the E.C.G. pattern alter. One patient became hypertensive but the blood pressure had begun to rise before the journey, and the rise seemed to result from an intravenous infusion of plasma and mannitol. No patient became hypotensive. Four patients developed delayed hypotension similar to that described previously (see fig. 3), but in three this was related to starting intermittent positive pressure ventilation (I.P.P.V.).

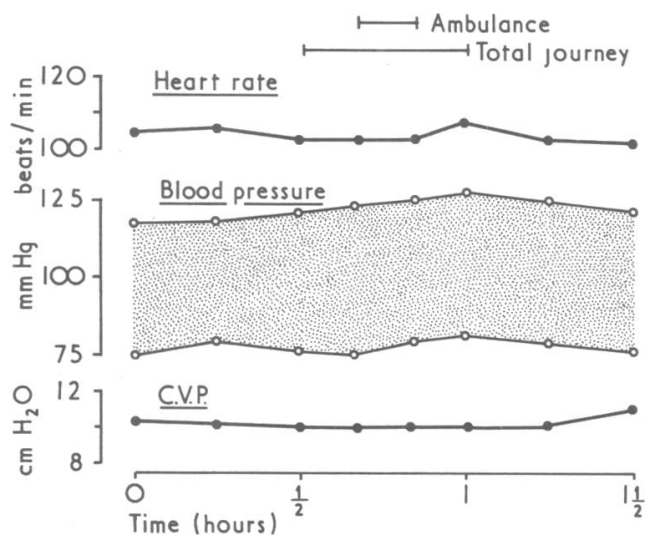

FIG. 4-Prospective study. Mean cardiovascular values of 20 critically ill patients.

There was no change in mean respiratory rate or arterial blood gases in the critically ill patients (table II). $\mathrm{Po}_{2}$ fell in one patient, and $\mathrm{PCO}_{2}$ rose in two, apparently because of with- drawal of oxygen therapy during the journey or the use of intravenous morphine.

Transfusion requirements slowly diminished with progressive resuscitation (fig. 5), the rate being uninfluenced by the journey. Urine production slowly increased, again uninfluenced by the journey.

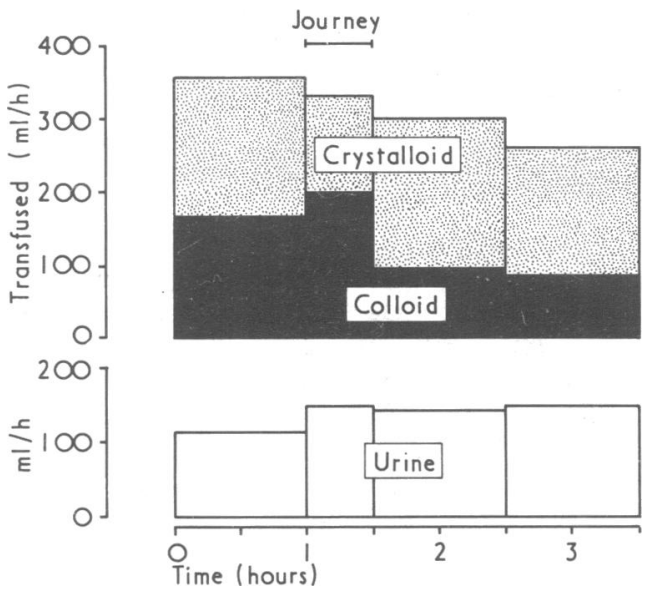

FIG. 5-Prospective study. Mean fluid balance of critically ill patients.

There was no change in mean rectal temperature in either the critically ill or the convalescent surgical group (fig. 6). No patient had a change of more than $0.5^{\circ} \mathrm{C}$. Both the critically ill and convalescent surgical groups had a comparable slight fall in toe temperature. Ambient temperature is also illustrated, the sharp falls corresponding to the moves to and from the ambulance.

One patient with a post-partum intracerebral haemorrhage had a fit 15 seconds after the ambulance moved off. Fits had been controlled with muscle relaxants and I.P.P.V. for the previous three hours.

A general comparison of the critically ill patients in the retrospective and prospective series is made in table III.

TABLE III-Comparison of Retrospective and Flying-squad Patients

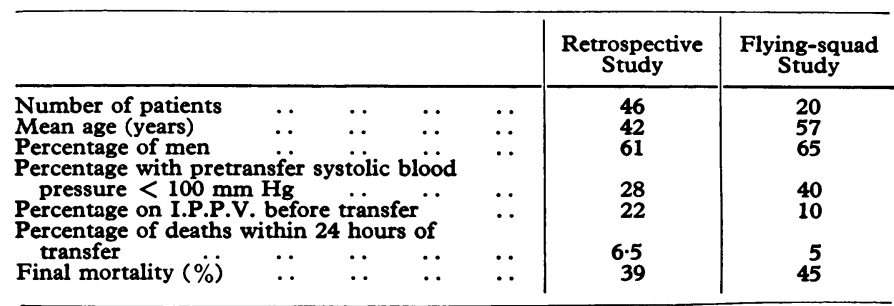

\section{Discussion}

The effect of an ambulance journey may be either direct or indirect. ${ }^{2}$. Discomfort, pain, and other stimuli may directly affect the patient's condition while lack of facilities and the motion of the ambulance may reduce the ability of the attendants to provide treatment.

In our retrospective study the incidence of major cardiovascular changes was comparable to that reported by other authors dealing with similar patients. ${ }^{58}$ No previous reports, however, have been made of hypertension or delayed hypotension though the former seems a natural response to the stress of transport. Delayed hypotension, though not strictly an effect of transport, can be regarded as a consequence of transfer to a different unit. The high incidence $(46 \%)$ of a raised arterial $\mathrm{PCO}_{2}$ after transport confirms the difficulty in assessing and 


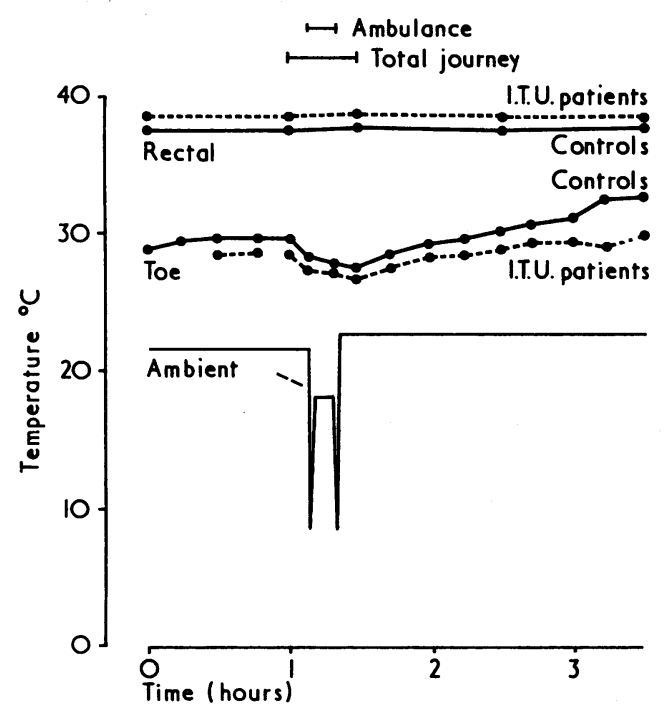

FIG. 6-Prospective study. Mean rectal and toe temperatures of 20 critically ill intensive therapy unit (I.T.U.) and 20 convalescent surgical patients (con-trols).

maintaining inspired oxygen and ventilatory requirements under these circumstances. The occurrence of fits has been noted previously. ${ }^{5}$ ?

In the prospective study there was a marked reduction in the number of patients who became hypertensive, and none became acutely hypotensive. Three of the four cases of delayed hypotension were related to beginning I.P.P.V. shortly after the patient reached the intensive therapy unit. All the instances of altered blood gases were related to changes in oxygen therapy or the administration of narcotics. The fit seemed to be a direct consequence of ambulance movement. It was rapidly controlled but might have been prevented by increased sedation before transfer, as shown by Poisvert." The slight fall in great toe temperature suggested mild peripheral vasocontriction, ${ }^{12}$ but the clinical significance of this observation is difficult to ascertain when ambient temperature is changing. All these effects, though potentially harmful, subsided either spontaneously or promptly in response to treatment. Thus, the 20 critically ill patients in the prospective study showed less frequent and less serious effects of the journey than those studied retrospectively. Most of the minor effects could be accounted for by changes in treatment during the journey or after arrival at the intensive therapy unit; evidence for the direct stress effects of the journey itself was minimal.

Several changes in procedure for the transfer of critically ill patients were introduced at the start of the prospective study. These included careful resuscitation before transfer, continuing medical care during the journey, and a slow gentle journey. The relative importance of each of these factors is uncertain but it is clear that their combined effect prevented the occurrence of serious complications in this group of seriously ill patients. The value of an experienced and properly equipped intensive therapy flying squad seems obvious. More detailed investigation of the in-transit phase of the ambulance journey and of journeys from more distant hospitals is in progress.

We are indebted to the medical and nursing staff of the intensive therapy unit, Western Infirmary, Glasgow, and the referring hospitals. The cardiology department of the Western Infirmary and the physiology department of Glasgow University kindly lent equipment. The ambulance and portering staff, especially at the Western Infirmary and Gartnavel General Hospital, Glasgow, were unfailingly helpful and patient.

\section{References}

1 Pantridge, J. F., and Geddes, J. S., Lancet, 1967, 2, 271.

2 Snook, R., British Medical fournal, 1972, 3, 574.

Lambrew, C. T., Experience of a mobile coronary care unit. Presented at the First International Symposium on Mobile Intensive Care Units, Mainz, Germany, 1973 .

4 Cullen, C. H., Douglas, W. I. C., and Danziger, A. M., British Medical fournal, 1967, 3, 438 .

5 Pichard, E., et al., Révue des Corps de Santé, 1970, 11, 611.

- Cara, M., et al., Anaesthésie, Analgésie et Réanimation, 1957, 14, 942.

7 Poisvert, M., Agressologie, 1962, 3, 592.

8 Cardoso, P., Annales Anesthesiologie Francais, 1964, 5, 645.

- Hurtaud, J. P., Annales Anesthésiologie Francais, 1965, 6, 281.

10 Radiguet, P., and Picard, P., Revue des Corps de Santé, 1967, 8, 65.

11 Redingham, I. McA., et al., Postgraduate Medical fournal, 1974, 50, 420.

12 Joly, H. R., and Weil, M. H., Circulation, 1969, 39, 131.

\section{Any Questions?}

We publish below a selection of questions and answers of general interest

\section{Triamcinolone in Hay Fever}

Under what circumstances is intramuscular triamcinolone acetate indicated for the treatment of hay fever in adults and children? What are the possible complications of using this treatment in children?

I assume that the questioner refers to triamcinolone acetonide (Kenalog), which is a "depot" corticosteroid similar to methylprednisolone acetate (Depo Medrone). Both of these are advertised for the treatment of hay fever. They are highly active systemic corticosteroids and are administered by subcutaneous injection in doses which will suppress the pituitary-suprarenal axis. The oral prednisone equivalent of $1 \mathrm{ml}$ of either of the above compounds would be $50 \mathrm{mg}$. The treatment of hay fever by corticosteroids in any form should seldom be necessary. The drugs should be reserved (on the grounds of their suprarenal suppressive side effects) for those patients who do not respond to simpler and safer methods of treatment, such as antihistamines and sodium cromoglycate. In some overriding social circumstances-for, instance, for honeymoons or important examinations, both of which are favoured during the "hay fever season" in June and July-there may be a case for the depot corticosteroids, but this is a matter of opinion. These drugs should be treated with the same respect and caution as is necessary when prescribing a course of oral corticosteroids for allergic disease. There are no reported side effects other than suprarenal suppression when they are given only once or twice, which is all that is required, or recommended, in hay fever. Under these circumstances there is no difference between adults and children. Long-term treatment with these drugs in perennial rhinitis is not recommended.

1 Ganderton, M. A., and James, V. H. T., British Medical foumal, 1970, 1, 267 